\title{
Critical Thinking: Frameworks and Models for Teaching
}

\author{
Mansoor Fahim ${ }^{1} \&$ Samaneh Eslamdoost ${ }^{1}$ \\ ${ }^{1}$ Allameh Tabataba'i University, Tehran, Iran \\ Correspondence: Samaneh Eslamdoost, Allalmeh Tabataba'i University, Tehran, Iran. E-mail: \\ samaneh.eslamdoost@gmail.com
}

Received: March 17, 2014 Accepted: May 23, 2014 Online Published: June 13, 2014

doi:10.5539/elt.v7n7p141 URL: http://dx.doi.org/10.5539/elt.v7n7p141

\begin{abstract}
Developing critical thinking since the educational revolution gave rise to flourishing movements toward embedding critical thinking (CT henceforth) stimulating classroom activities in educational settings. Nevertheless the process faced with complications such as teachability potentiality, lack of practical frameworks concerning actualization of CT tasks, and transferability obstacles, as well as lack of a homogeneous model of conceptualization of CT among educators. The present study made an effort to represent a comprehensive model of CT for educators drawn on the contemporary literaturein order to indicate a uniform delineation of the construct and to offer a comprehensive model of CT for the intention of making boosting learners' capability of CT possible.
\end{abstract}

Keywords: critical thinking, critical thinker, framework, model

\section{Introduction}

Critical thinking has become the focus of attention since 1960s notified and tracked by the educators' becoming thoughtful about students' incapability ofhigher order thinking or critical thinking. Followed that, there was a secondly rated concern, which was about a definite framework or a model to teach critical thinking that was well underestimated and also uncertainty prevailing as terms feasibility of transferability and generalizability of critical thinking strategies to similar contexts of education are brought forward.

This paper is a humble effort to clarify what CT and CTers' characteristics are, to introduce the models proposed for the application of CT in educational settings, and to indicate how CT could be taught in educational settings.

\section{Review of the Related Literature}

\subsection{Critical Thinking and Critical Thinkers}

There have been lots of definitions of CT recently developed with more or less overlap. The first step in order to uncover the characteristics of a CTer is considering the main definitions of the concept of the CT proposed by many scholars recently. A groundbreaking and early definition of CT was proposed by Bloom (1956) as CT is the mastery of a set of skills such as knowledge, comprehension, application, analysis, synthesis, evaluation, and applying the best when faced with a novel situation; furthermore, the three higher levels, i.e. analysis, synthesis, and evaluation, are frequently reported to reflect CT. Later, Ennis (1987) explains CT as the combination of deposition or habits of using skills in addition to skills introduced by Bloom (1956). Besides, Ennis (1987) declares that CT is reasonable and reflective thinking. Moreover, CT in Pauls' (1993) definition is taken to mean as the ability to take charge of one's own thinking, assessing, and evaluating the effectiveness of thinking according to the purpose and developing a criterion for constant evaluation which is basedon logic.As put by Chance (1986) CT is admittedlythe ability to analyze facts, generate and organize ideas, defend opinions, make comparisons, draw inferences, evaluate arguments, and solve problems. By the same token, CT is a way of reasoning that demands adequate support for one's beliefs and disinclination to be convinced unless sufficient evidence is found.

One also should not overlook the fact that $\mathrm{CT}$ is a path through reasoning, scientific and analytic method of analyzing the issue, gathering evidence, assessing the evidence, argument, and knowledge impartially, as well as concluding. In this connection, the analysis of evidence probes into deeper levels of conceptualization and assumptions. It is also worth mentioning that CT or thinking about thinking is mostly associated with Piaget's formal operation stage in which the child isable to follow complex rules and logic. On the other hand, thinking 
about one's own thinking is supplementaryto cognitive operations that do not exist in lower order cognition. Needless to say that CT involves the logical reasoning, an ability to separate facts from opinions, examining and questioning things before accepting them (Wood, 2002, in Fahim \& Pezeshki, 2012). In this regard the process of formal reasoning which incorporates CT is designated by Nugent and Vitale (2008, in Fahim \& Pezeshki, 2012) comprising problem solving, decision making, diagnostic reasoning thus incorporating the scientific method. It follows that $\mathrm{CT}$ "includes both cognitive competencies and personal competencies which interact with each other Each of these competencies involves different components all of which are in constant interaction with one another. Cognitive competencies include having the ability to dissect, modify, analyze, interpret, examine, and correlate, synthesis, summarize, understand and make inferences and generalizations. Personal competences on the other hand include being tolerant of ambiguity, thinking independently, having perservance, being self-confident, inquisitive, motivated, risk taker, reflective, creative, and curious" (Fahim \& Pezeshki, 2012, p. $155)$.

Successively, Fahim and Azarnioushi (2011) identify CT as a way to establish a disciplined executive level of thinking to our thinking, more to the point, a powerful inner voice of reason to monitor, assess, and reconstitute our thinking. In addition, Benesch (1999) defines CT as becoming aware of the assumption under which we think and act. In fact, Beach (2004) discusses about a close relationship between CT and Socratic Questioning and declares that it adds systematicity and profundity in evaluation of the conceivable approximation of truth and reality.

Kuhn (1999) declared that CT is directly related to metacognitive competencies or higher-order thinking skills which help the individuals to know about their knowing and that of others which is in contrast to lower order thinking. Kuhn's meta-knowing entails metastrategic skills which are closely related to the procedural knowledge, metacognitive which is closely associated with the declarative knowledge and epistemological which is relatedto the broader understanding of knowledge. Kuhn professed that the development of metacognitive understanding is essential to $\mathrm{CT}$ advancement. Among all, strictly speaking, metacognition, a protruding constituent, which is in contrast to first ordered or better to say lower-level cognitive skills, strongly assumed to be a higher-ordered cognitive skill, entails knowing about one's own knowing. Drawing on what Paul (1990, cited in Kuhn, 1999) stated "CT is thinking about your own thinking" (p. 32). Therefore, admittedly, a strongly established tenet could be settled about a close association between metacognitive knowledge and CT skill. In this respect, Kuhn (1989) believes that students should gain control over their process of employing strategies in coordinating existing understanding with new evidence because "it has to do with awareness, understanding, and management of ones cognition" (p. 18). This is what is called meta-knowing.

\subsection{Why and How to Teach CT?}

Broadly speaking, CT, despite fostering the analytic and scientific thinking in individuals, has its profound effects in social life of every human being to have a better life (Paul, 1993 \& Nickerson, 1987). It is hard to escape the obvious fact that thinking is the main activity in human being, a distinguishing part that makes a human A HUMMAN. Suffice it to say it is a way to move toward self-actualization in every human being. However, CT is widely a neglected area in educational system (Kennedy, 1991; Paul, 1993; Nickerson, 1987). In other words, most educators focus on transferring established and a priori knowledge or the content matter rather than instructing techniquesto individuals to think so as toturn out to beautonomous learners.

Since 1980, the great revolution occurred in educational setting regarding embedding explicit teaching of CT into the classroom. The great shift from knowledge based instruction to a novel approach in which the main focus is to foster thinking ability of learners occurred as a result of the fact that educators noticed students had grew into inactive learners who are only capable of absorbing pre-planned amount of knowledge which is transferred to them. Despite the great shift in the acknowledgement of the significance of thinking ability, CT is barely taught directly in educational setting in a systematic way (Chaffee, 1992). The main concern since then was to devise strategies and techniques of how to transform important instructional objectives in real activities integrated into classrooms. On balance the educator has to lead students from the most important skill of thinking and reasoning to the most complex form of cognitive skills that is knowledge, comprehension, application, analysis, synthesis and evaluation followed by logical reasoning and decision making. Furthermore, the instructor has to use laws of logic to help students to evaluate proposition. By way of example, Nickerson (1987) declares that the main objective of the instructor has to be to assist students not to think at goals but to think about goals, that is not merely evaluating the propositions or vertical thinking (DeBono, 1971), to put it bluntly, it has to do with transferring the skills of forming creatively and generatively new propositions.

$\mathrm{CT}$ is becoming a flourishing field in educational system. Educators have agreed on the focal role of CT because 
of the fact that learners need to be put in an active position in learning process in order not to be reflexive addressees and receptive of knowledge which is transferred from the mere authority of the class for satisfying the course objectives which is the out-weighing preference in educational settings. The established information blocks the process of nurturing learners to critically discern and analyze the information vigorously. It is generally accepted that routinized, teacher directed, score oriented trends do not yield CTers necessarily which ultimately leads to score dominated courses (Fahim \& Khatib, 2012). According to Fahim and Khatib (2012), beyond question, score dominated courses "have succeeded to do in training students as CTers is teach them consider course significant points and teachers' interests and emphasized areas which are believed to be included in the exams and scoring" (p. 80).

Given the fact that CT is a perspective that has been largely absent in educational systems, currently, most educators favor the view that CT skill must be taught (Perkins \& Salmon, 1989; Presseisen, 1988). Taken into consideration that children cannot be expected to progress in their development of thinking unless a kind of intervention is present, the instructor has to engage the students in learning about meaningful, rich, domain specific subject matter (Brown, 1997). According to Walsh and Paul (1988) CT is not the same as intelligence and does not develop with maturity butit must be taught because of the fact that learners do not just pick up CT.

As a result of the great revolution in the educational system, CT has got centrality in the realm of education (Gelder, 2005). Arend (2009) puts emphasis on the fact that CT has to be conceptualizedas the goal of the education and in this regard educators should overtly teach CT strategies. Dressel and Mayhew (1954) believed that educational institutions are responsible for teaching students to go beyond the simple and mental activities. By the same token, Kuhn (1999) highlights the importance of "CT in two grounds: conceptual and practical. Conceptually, it is essential that we know what we mean when we refer to CT or CT skills if the constructs are to be useful" (p. 17). Kuhn (1999) believes that in education before we teach CT we have to see what CT is. On the other hand, as Simpson and Courtney (2002) asserted, CT is not just the accumulation of individual components into a whole, but it's a developmental process rather that a product or method to be learned. The component of a theoretical model have to be put into practice in order to actualize the ultimate goals of a CT model, to be explicit, to promote individuals' strategies of logical and critical thinking to become full-grown CTers.

Traditionally it was belied that CT is a set of mental competencies that is more or less inherent. Yet, newer-situated-cognition regard intellectual skills as obtained capability which arise as a result of practice (Cole, 1996; Resnick \& Nelson-Le Gall, 1997; Rogoff, 1998, cited in Kuhn, 1999). Until a construct is defined conceptually, one cannot investigate its generalizability and transferability. It became apparent that the issue of transferability and generalizability of CT skill is determined by a comprehensive and a brilliant definition of the construct of CT. The next step is to call the practicality of the issue into question or better to say to make the constructs concrete for the educators. It is beyond doubt that teachers have been presented a little in the way of concrete frameworks and models of CT skills and associated practices in a real educational setting.

However, the rapid shift in education made many scholars to highlight the prominence of the effectiveness of instruction on CT ability (Perkins, 1987; Hernstein, et al., 1986; Royalty, 1995; Lehman \& Nisbett, 1990). Among others, Perkins (1987) discusses about three stages of CT development including acquisition, making it automatic and transferring CT ability to similar contexts.Unfortunately, most programs focus on acquisition and do not foster students' capability of making CT ability procedural and a persistent, lifelong ability.

When seen in light of that the main aim of an educational system is to promote students to become cautious and potent thinkers; therefore, the serious and final goal of an educational system becomes to develop competencies that empower students to participate fully as better citizens. Accordingly, the attempt has always been establishing a knowledge based approach. However, systematic and extensive empirical research on the nature of thinking and the way to transform $\mathrm{CT}$ and its development has not got sufficient attention.

It is difficult to resist the idea that CT instruction would not beoperative if is taught in isolation. There is a general consensus that it must be holistic and integrated component, a fit to the whole. Therefore, teachers have to integrate CT skills in content material. Moreover, they have to provide opportunities for the students to identify the material that they are working with, analyze it, characterize it, and consider similarities and differences between them. Regarding how to embed CT activities in classroom activities Carr (1998, cited in Vera Schneider, 2002) outlines the techniques such as: providing time and space for brainstorming through discussions, not to find solutions for students, except they have to identify tasks and a problem to solve for them, providing opportunity for the students to compare and contrast and categorize matters at hand, and finally encouraging creativity and preventing teacher-prepared projects.

Although there is a great agreement on the importance of teaching CT, unquestionably theforemost challenge 
educators' face with is linking CT with subject mattersand the problem of transferability. The evidence from the previous studies confirm the fact that $\mathrm{CT}$ skill can be learned and transferred to novel situations when students receive explicit instruction (Bangert-Drowns \& Bankkert, 1990; Cotton, 1991; Dwech, 2002; Halpern, 1998, 2003; Marin \& Halpern, 2011; Kuhn, 2000; Moseley et al., 2005). When CT skills such as metacognition are explicitly taught through a guided instruction in which students are responsible for their own learning process, these skills become internalized. Regarding the problem of transferability, Perkins, Jay, and Tishman (1993, cited in Kuhn, 1999) declare that CT entails deposition as well as the skills to think well. Our problem arises in the definition of the depositions because people think critically not out of habit or a deposition. Considering the importance of deposition the issue of meta-knowing is highlighted. So the importance of social practice can be recognized without ignoring the knowing and meta-knowing, powers that leads to their individual and collective behavior. Therefore, in an educational setting what is being transferred and skills and exercises that reinforces the skills play a major role. In this regard, the ultimate intention has to be training individual to be in charge of their metacognitive and metastrategic control of their own knowledge.

Swatz (2003, cited in Marin \& Halpern, 2011) discusses about three key principles of CT instruction reflecting the need for both explicit and implicit strategies: a) the more explicit the teaching, the greater the impact on the students; b) the more classroom instruction incorporates an atmosphere of thoughtfulness, the more open students will be; c) the more teaching of thinking is integrated into content instruction, the more students will think about their own leaning.

In the same vein, regarding the best fit of CT instruction in an educational setting, Marin and Halpern (2011) put forth two distinct philosophies. The first one is "embedded approach in which the course structure and the teacher advance higher order thinking without direct instruction" and the second one is the "explicit approach in which specific skills is taught" (p. 3). In teaching CT two very important factor should be taken into consideration (Marin \& Halpern, 2011), namely, to learn CT and repeated practice. All in all, to learn CT is defined as identifying content and skill, design and delivery, on the other hand repeated practice is greatly dependent on the context and requires deliberate effort. In this regard, it is worth mentioning Marin and Halpern's (2011) notion of effective instruction that comprises of factors such as: repeated encouragement of understanding, deliberate practice, and providing students with the opportunities to transfer their knowledge.

With regard to major factors in CT instruction process, different scholars draw our attention to a number of outcomes such as: the explanation of benefits of the particular skills (Baker \& Brown, 1984); clarification of the use of skill in other contexts (Feurestein, 1980; Perkins \& Salomon, 1989); stimulating the background knowledge of students (Ausubel, 1960; Mayer, 1983); emphasizing and encouraging the importance of metacognition (Beyer, 2001; Costa, 2001; Halpern, 2003; Staib, 2003) and modeling reflective thinking by instructors (Costa \& Kallick, 2000), (all cited in Marin \& Halpern, 2011). Effective practice of CT in an educational setting could also include using real-life issues when teaching problem-solving skill because of the fact that applying real-world issues will pave the way for the students to be capable of transferring the CT skills to diverse contexts (Stenberg, 2011).

Gelder (2005) provides us with an in-depth analysis of the fact that how we could improve our teaching and educational program. He mentions that cognitive science which is providing us with some incomplete insights cannot account for the whole image. Actually, cognitive science provides general and theoretical information, but not any detailed recipes for actual and practical teaching. In view of that, the findings of cognitive science must be judiciously correlated with practical issues that provide teachers with a sound framework. The fact that cognitive scientists do not study CT as a topic in its own right is because the topic is too broad and cognitive scientist focus only on techniques. Gelder (2005) represents six reasons regarding CT as a convincing typical and comprehensive framework to empower students with the rigorous thinking strategy:

Lesson 1. CT is a hard and a complicated process. Gelder summarized Kuhn's (1991) findings: a) most people rely on general reasoning and argumentation; b) humans are basically critical; c) human beings favor issuesthat make sense. d) higher order thinking or CT thinking is built up out of simpler skills but which become complicated when combined into higher order skills; e) CT needs a long time to develop.

Lesson 2. Practice makes perfect. CT needs to be taught explicitly and practiced

Lesson 3. Practice for transfer. Learners need to be instructed to transfer CT through some steps: "a) have students practice a primary CT skill; b) get them to abstract for themselves the skill; c) challenge them to identify some other content domain in which the abstracted skill might be properly applied" (p. 43).

Lesson 4. Practical theory. Because of the fact that knowing about something makes you to do things you cannot otherwise do.In this regard, CT ersneed to understand the theory of CT. 
Lesson 5. Map it out. CTer need to picture an outline of the logical structure of the issue which is to be analyzed.

Lesson 6. Brief presentation. CTer should be aware of the possible errors to either eliminate them or compensate for the effect.

What is most agreed upon is that CT needs to be taught and is not an inborn capability (Schafersman, 1991; Wood, 2002). In this regard, the burden is laid on educators who may have the ability to think critically but possessing the ability does not suffice; they should be capable of passing it on to learners (Facione, 2011). Furthermore, they must be able to practice the skill of transferring CT ability to other contexts (Pikkert \& Foster, 1996). In this connection, the educators are required to devise activities that stimulate and inspire the skill of CT in learners through repeated practice to become an automatic ability within the individuals. One of the major activities that chiefly contribute to developing and broadening CT ability of learners is writing. Writing, especially persuasive writing and argumentative wiring, can promote students' CT skill. It is an inevitable fact that writing is the finest way to make students spontaneously express their own ideas about a topic in an ordered and organized way. It is reasonably supposed that writing is the act of understanding itself. Throughout a writing activity students might be asked to make value judgments about a piece of writing and come to a conclusion through logical reasoning (Schefersman, 1991).

Regarding the kind of activities that contribute to CT different research findings have been reported such as analyzing argument (Facione, 1990; Halpern, 1998), making inferences (Paul, 1992; Willingham, 2007), judging or evaluating all aspects of argument (Case, 2005; Lipman, 1988), making decisions or solving problems (Ennis, 1985; Halpern, 1998; Willingham, 2007), interpreting and explaining (Facione, 1990), and asking and answering questions (Ennis, 1985).

Fahim and Mirzaii (2013) introduce dialogic CT as a new method of instructing CT in an educational setting. The authors analyze the effect of writing instruction and dialogic CT on argumentative writing of EFL learners. In dialogs students recreate meaning; this process leads to a thorough understanding on the part of the students about a topic. The interlocutors in a conversation test their ideas through feedbacks they get and develop new ones. This interaction affects the overall cognitive systems of students. Consecutively, interactions stimulate thinking and expansion of knowledge. It also transforms social relations and the feeling of becoming a member of the group in the process of dialogic CT. The results revealed that both experimental groups outperformed the control group but the experimental group who received both dialogic $\mathrm{CT}$ and argumentative writing performed better.

It is widely accepted that "it's the duty of the teacher to implicitly ask students to attend to strategies of CT and to evaluate each reasoning and argument on a multi-dimensional level before accepting it as correct" (Fahim \& Khatib, 2012, p. 82). Activities that were distinguished as beneficial by some scholars in this regard are subdivided to the followings:

- The class starts with students' voluntary expressions of their comprehension of the text and what they thought the author was trying to convey (Brookfield, 2012).

- Group discussions are encouraged by the instructor (Wallace, 2003; Rasool et al., 2002).

- Collaborating in interpreting a text or "critical analysis of other people's reasoning" (Cotrell, 2005).

Fahim and Khatib (2012) during a course of English literature triedto empower language learners to critically analyze literary texts and freely express their own thoughts and perceptions about the texts which are informed by and followed their perceptions. Due to the great potentiality of literary texts during the course of literature the researchers attempted to provoke students' critical thoughts by stimulating skills in order to enable them to analyze a text and interpret different perspectives embedded in a literary text. The findings of the study put emphasis on not only teachability of CT but also on the fact that CT or higher order thinking fosters students' comprehension of vastly demanding texts.

Good CTers are good questioners. They constantly observe, analyze, and search for explorations. Good questions that provide the opportunity for the deeper thought is the major concern. Recently, Socratic Questioning has been known as a CT teaching strategy. Socratic questions are considered as systematic questions which foster students' awareness of ignorance, misconceptions, wrong assumptions, and false conclusions. The questions do not have a definite answer; on the other hand, they stimulate thinking. The students' answers are followed by a teacher feedback, not a definite remark, though. It's a strategy to collect thoughts and build a new understanding from previous knowledge. In the process of nurturing individual learners' CT ability teachers' art of questioning is a vital factor. Therefore, this can be seen as a skill that needs to be developed and at the same time automatized. A major prerequisite for this issue is that teachers have to be talented in asking questions. Fahim and Ahmadian 
(2012) present intellectual resources required for a CTer: background knowledge, operational knowledge of the standard of good thinking including standards that are relevant to judging intellectual practice and principles that are relevant to guiding practices of deliberation of inquiry, heuristics, and habits of mind.

A considerable amount of literature has been published on the effect of CT on language proficiency by many investigators and in numerous studies plentiful contributing factors have been identified, among all Sheikhy Behdani (2009) found a positive effect of CT on reading comprehension; Mirzaie (2008) argued the effect of CT and lexical inference; Kamali and Fahim (2011) investigated the impact of CT and resilience on reading comprehension containing unknown words. The results showed that high level of CT ability and resilience can affect academic performance and it contributed to the competence of reading; Fahim and Sa'eepour (2011) concluded that $\mathrm{CT}$ is a significant factor affecting reading, they also discussed about the effect of debate which largely triggers the learners' CT; Fahim and Azarnioushi's (2011) studydemonstrated the positive effect of CT on grammar test scores. Fahim and Bagheri (2012) highlighted the importance of the kind of activities to foster CT in classroom and introduce active reading, free discussions, analytic writing, and dynamic assessment as some techniques that contribute to CT.

\subsection{Models and Frameworks for Teaching CT}

In the field of education a variety of models for teaching CT has been developed. Some scholars (Bullen, 1997, 1998; Clulow \& Brace-Govan, 2001; Garrison, Anderson, \& Archer, 2001; Henri, 1992; Newman, Webb, \& Cochrane, 1995; Norris \& Ennis, 1989) tried to propose a short but comprehensive model. Despite the fact that research has not been consistent in the introduction of a stable model, there can been seen a great deal of overlapping in some models developed for the common ambition of inserting CT activities in educational settings. It is necessary here to indicate some of the models represented by various scholars. Norris and Ennis (1989) introduce a five step model to satisfy the requirements of a CT inspiring course. The steps comprise ofelementary clarification, basic support, inference, advanced clarification, strategies, and tactics successively. Moreover, Henri (1992) and Clulow and Brace-Govan (2001) have conclusively shown major contributing factors as elementary clarification, in-depth clarification, inference, judgment, and strategies. Another model illustrated by Garison, Anderson, and Archer (2001) puts emphasis on features such as triggering events, exploration, provision, and resolution. Likewise, Newman, Webb, and Cochrane (1995) picture classroom activities that leads to the development of CT in individual learners as beginning with the clarification of the issue by the instructor followed by in-depth analysis of the issue which paves the way to making inferences and interpretations. The process will successively lead to making learners to be capable of formulating their own judgments and lastly become independent strategy developers for their lifelong thinking skill. In 1997, Bullen categorized the CT stimulating activities into classification of the information available, gathering authentic evidence as well as evaluating it, making inferences and judgments on the basis of the firmly established evidence, and eventually drawing best strategies and techniques as a thinking strategy. Perkins and Murphy (2006), in a model similar to Bullen's, introduced a five step technique to embed CT stimulating instruction in educational setting comprising clarification, assessing evidence, inference, and strategy building.The first step includes clarification of everything involved,such as describing, and defining the issue. In assessment the students are to be empowered to cover various types of judgment, including the use of the evidence to support or refute judgment. The next step which is making inference contains application of thinking skills such as induction and deduction. In the final step strategies are to be formulated by individuals based on their perceptions of the previous steps including both tactics and planning practical purposes.

Ennis (1989) introduced an illustration that suggests three models: a general, an infusion, and a mixed-model toward CT instruction. General approach is taken to mean teaching generalized CT skills in a CT course. Additionally, infusion approach is suggestiveof required self-consciously teaching CT skills form within subject course. Eventually, a mixed-model approach is introduced as a combination of a general course with either an infusion or immersion approach. In the same vein, Perkins and Murphy (2006) discuss that in a model of CT theoretical compatibility and practicality must be weighed in making the selection of processes to be included. Each process might be chosen to assess a group as opposed to individuals, so simply choosing a list form the literature does not suffice. Researchers might use a list of processes for their present purpose.

According to Halpern (1998) a depositional or attitudinal component, that comprises of modeling CT and actively inspire thoughtful responding, is compulsory. In this regard theexplicit instructionof CT skills including structured training activities designed to facilitate the transfer of CT techniques across innumerable contexts as well as nurturing metacognitive strategies which include having students discuss the process of thinking is mandatory. 


\subsection{Evaluating $C T$}

A value-laden model of education needs to be made operationalized for the intention of putting theory into practice and ultimately assessed in order to provide instructors and learners the essential weightings and feedback. Baron (1987) introduces four dimensions in evaluating CT teaching programs including formative-summative, product-process, qualitative-quantitative, and experimental-quasiexperimental classifications. Additionally, Fahim and Pezeshki (2012) used RACE model that is introduced by Nugent and Vitale (2008) and is to make the learners "recognize the information in the item then" make them ask"what the question is asking, next try to critically analyze the options available and finally eliminate as many options as possible" (p. 156).

Considering the challenges in evaluation it is widely believed that pre-test and post-test results in evaluating CT skill do not reveal retention.Cognitive skills improve with practice and real effects of CT will be apparent some time later, while, long term retention is difficult to assess. As a result, teaching-testing approaches in classroom can be changed in different ways to improve CT ability in students (Schefersman, 1991).

\section{Conclusion}

To sum up a model of CT needs to foster cognitive characteristics of individual learners. In this connection, an instructional model of $\mathrm{CT}$ is required to comprise instruction and practice phases. As it was thoroughly discussed before, the logic for the instruction of CT is that a systematic way of intervention is mandatory to assist the individual learners to reach their potential zone of proximal development in their higher-order thinking ability. The author believes that each of the components discussed above are central in taking over one's thinking. The strategies that are indispensable to be taught in the instruction phase have to comprise:

1) Clarification:

a) Questioning: doubting and searching the fundamentals related to the problem.

b) Outline: making a bright sketch of cognitive structure.

c) Authentic evidence: gathering the related and supportive evidence as well as counter evidence.

2) Judgment:

a) Selecting the best and greatly related as well as most supportive evidence.

b) In-depth analysis of the supportive and counter evidence.

c) Considering values, standards, and urgencies as well as noteworthy and vital points.

d) Exhaustive analysis of the arguments and counter arguments.

3) Strategies:

a) Have a clear definition of the matter at hand.

b) Distinguishing the very purpose of the issue.

c) Make adaptations between the purpose and evidence as well as values.

d) Make value-laden inferences on the basis of previous findings.

e) Not to claim a definite inference: Have an evolving and iterative rethinking over the issue in order not to propose a fixed deduction.

In clarification phase the intervention of the instructor is essential at the beginning stages. The instructor can provide the learners with the opportunities like raising vital and critical questions and brainstorming the issue for the intension of enhanced illumination, description, and explanation of the matter at hand for the aim of helpinglearners to categorize the outline of the problem. Subsequently, learners need to become autonomous followers of the process by independently gathering the supportive proof for the aim of restricting and narrowing down the outline to the least logical and feasible outline of the statements regarding the evidence, values, arguments, and counterarguments. This phase needs to be practiced and made automatic during various problem solving tasks.

Regarding the transferability of the CT skill to various similar and non-similar contexts the elements of CT skills, namely question, outline, evidence, analysis, values, arguments, counterarguments, purpose, adaptation, inference, and iterative thinking, need to be taught and automatized in individuals because of the fact that CT is an issue-specific method of thinkingso in order to deal with the problem of generalizability the elements of CT skill need to be explicitly made automatized in individuals as a systematic way of thinking imprinted within the 
minds of individual learners from which they can make use of on the occasion of confronting with any issue. In this case, CT would become a lifelong and persistent automatic ability in individuals. Instruction of CT is required to be as comprehensive, systematic, and at the same time, integrated way of thinking applicable to any problem. In this respect, leaners are required to be capable of analyzing the issue, comparing and contrasting, finding the critical points, and making value judgments.

\section{References}

Arend, B. (2009). Encouraging critical thinking in online threaded discussions. Journal of Educators Online, 6(1), 1-23. Retrieved from http://www.files.eric.ed.gov/fulltext/EJ904064

Ausubel, D. P. (1960). The use of advance organizers in the learning and retention of meaningful verbal material. Journal of Educational Psychology, 51, 267-272.

Baker, L., \& Brown, A. L. (1984). Metacognitive skills and reading. In P. D. Pearson, R. Barr, M. L. Kamil, \& P. Mosenthal (Eds.), The handbook of reading research (pp. 353-394). New York: Longman.

Bangert-Drowns, R., \& Bankert, E. (1990). Meta-analysis of effects of explicit instruction for critical thinking. Paper presented at the annual meeting of the American Educational Research Association, Boston, MA. Retrived from http://www.files.eric.ed.gov/fulltext/ED328614.pdf

Baron, J. B. (1987). Evaluating thinking skill in the classroom. In J. B. Baron, \& R. J. Stenberg (Eds.), Teaching Thinking Skills: Theory and Practice (pp. 221-247). New York: W. H. Freeman \& Company.

Beach, D. (2004). The role of Socratic questioning in thinking, teaching, \& learning. Retrieved from http://www.criticalthinking.org?resources/articles/the-role-socraatic-questioning-ttl.shtml

Benesch, S. (1999). Thinking critically, thinking dialogically. TESOL Quarterly, 33(3), 573-580.

Bloom, B. S. (1956). Taxonomy of educational objectives: The classification of educational goals. New York: David McKay.

Brookfield, S. D. (2012). Teaching for critical Thinking. San Francisco: John Wiley \& Sons, Inc.

Brown, A. (1975). Transferring schools into communities of thinking and learning about serious matters. American Psychologist, 52, 399-413. Retrieved from http:/www.psy.cmu.edu/ siegler/423brown97.pdf

Bullen, M. (1997). A case study of participation and critical thinking in university-level course delivered by computer conferencing (Unpublished doctoral dissertation). University of British Colombia, Vancouver, Canada. Retrieved from http://www.cstudies.ubc.ca/ bullen/publication.html

Bullen, M. (1998). Participation and critical thinking in online university distance education. Journal of Distance Education, 13(2), 1-32. Retrieved from http://www.jofde.ca/index.php/jde/article/view/140/394

Case, R. (2005). Moving critical thinking to the main stage. Education Canada, 45(2), 45-49.

Chaffee, J. (1992). Teaching critical thinking across the curriculum. New Directions for Community Colleges, 77, 25-35.

Chance, P. (1986). Thinking in the classroom: A survey of programs. New York: Teachers College, Colombia University.

Clulow, V., \& Brace-Govan, J. (2001). Learning through bulletin board discussion: A preliminary case analysis of the cognitive dimension. Paper presented at the Moving Online Conference 2nd, September 2-4, 2001, Gold Coast, Australia.

Cotton, K. (1991). Teaching thinking skills. Retrieved from http://hppa.spps.org/uploads/teaching_thinking_skills.pdf

Cottrell, S. (2005). Critical Thinking Skills: Developing effective analysis and argument. New York: Palgrave MACMILLAN.

DeBono, E. (1971). New think: The use of lateral thinking in the generation of new ideas. New York: Avon Books.

Dressel, P. L., \& Mayhew, L. B. (1954). General education: Exploration in education. Washington, DC: American Council on Education.

Dweck, C. S. (2002). Beliefs that make smart people dumb. In R. J. Sternberg (Ed.), Why smart people can be so stupid. New Haven, CT: Yale University Press.

Ennis, R. H. (1987). Taxonomy of critical thinking deposition and abilities. In J. B. Baron, \& R. J. Stenberg 
(Eds.), Teaching Thinking Skills: Theory and Practice (pp. 9-26). New York: W. H. Freeman \& Company.

Facione, P. A. (1990). Critical thinking: A statement of expert consensus for purposes of educational assessment and instruction. Millbrae, CA: The California Academic Press.

Facione, P. A. (2011). Critical thinking: What is it and why it counts. Retrieved from http://www.insightassessment.com/content/download/.../what\&why2010.pdf

Fahim, M., \& Ahmadian, M. (2012). Critical thinking and Iranian EFL context. Journal of language teaching and research, 3(4), 793-800.

Fahim, M., \& Azarnioushi, S. (2011). The relationship between critical thinking and deductive/inductive teaching of grammar to Iranian EFL learners. The Iranian EFL Journal, 7(2), 180-195.

Fahim, M., \& Bagheri, M. (2012). Fostering critical thinking through Socrates' questioning in Iranian language institute. Journal of Language Teaching and Research, 3(6), 1122-1127.

Fahim, M., \& Khatib, S. (2013). The effect of applying critical thinking techniques on students' attitudes toward literature. International Journal of Applied Linguistics \& English Literature, 2(1), 80-84.

Fahim, M., \& Mirzaii, M. (2013). Improving EFL argumentative writing: A dialogic critical thinking approach. Iranian Journal of Research Studies in Language Learning, 1-18.

Fahim, M., \& Pezeshki, M. (2012). Manipulating critical thinking skill in test taking. International Journal of Education, 4(1), 153-160.

Fahim, M., \& Sa'eepour, M. (2011). The impact of teaching critical thinking skills on reading comprehension of Iranian EFL learners. Journal of Language Teaching and Research, 2(4), 867-874.

Feuerstein, R. (1980). Instrumental enrichment: An intervention program for cognitive modifiability. Baltimore, MD: University Press.

Garison, D. R., Anderson, T., \& Archer, W. (2001). Critical thinking, cognitive presence, and computer conferencing in distance education. Internet and Higher Education, 11(2), 1-14. Retrieved from http://cde.athabascau.ca/coi_site/documents/Garrison_Anderson_Archer_CogPres_Final.pdf

Gelder, T. V. (2005). Teaching critical thinking: Some lessons from cognitive science. College Teaching, 53(1), 41-46. Retrieved from http:/www.reasoninglab.com/wp-content/uploads/2013/10/Tim-van-GelderTeaching-CT-Lessons-from-Cog-Sci.pdf

Halpern, D. F. (1998). Teaching critical thinking for transfer across domains: Dispositions, skills, structure training, and metacognitive monitoring. American Psychologist, 53(4), 449-455.

Halpern, D. F. (2003). Thought and knowledge: An introduction to critical thinking (4th ed.). Mahwah, NJ: Lawrence Erlbaum Associate.

Henri, F. (1992). Computer conferencing and content analysis. In A. R. Kaye (Ed.), Collaborative learning through computer conferencing: The Najaden papers (pp. 115-136). Berlin: Springer-Verlag.

Hernstein, R. J., Nikerson, R. S., de Sanchez, M., \& Swets, J. A. (1986). Teaching thinking skills. American Psychologist, 41(11), 1279-1289.

Kamali, Z., \& Fahim, M. (2011). The relationship between critical thinking ability of Iranian EFL learners and their resilience level facing unfamiliar vocabulary items in reading. Journal of Language Teaching and Research, 2(1), 104-111.

Kennedy, M. (1991). Policy issues in teaching education. Phi Delta Kappan, 72(9), 661-666.

Kuhn, D. (1989). Children and adults as initiative scientists. Psychological Review, 96, 674-689.

Kuhn, D. (1991). The skills of argument. Cambridge: Cambridge University Press.

Kuhn, D. (1999). A developmental model of critical thinking. Educational Researcher, 28(2), 16-46.

Kuhn, D. (2000). Metacognitive development. Current Directions in Psychological Science, 9, 178-181.

Lehman, D. R., \& Nibett, R. E. (1990). A longitudinal study of the effects of undergraduate training on reasoning. Developmental Psychology, 26(6), 952-960.

Lipman, M. (1988). Critical thinking: What can it be? Educational Leadership, 46(1), 38-43. Retrieved from http://www.ascd.org/ASCD/pdf/journals/ed_lead/el_198809_lipman.pdf

Martin, L. M., \& Halpern, D. F. (2011). Pedagogy for developing critical thinking in adolescents: Explicit 
instruction produces greater gains. Thinking Skills and Creativity, 6, 1-13.

Mayer, R. E. (1983). Thinking, problem solving, cognition. New York: Freeman.

Mirzaii, Z. (2008). The relationship between critical thinking and lexical inferences of Iranian EFL learners (Unpublished master's thesis). Islamic Azad University, Science and Research campus, Tehran, Iran.

Moseley, D., Baumfield, V., Elliott, J., Gregson, M., Higgins, S., Miller, J., \& Newton, D. P. (2005). Frameworks for thinking: A handbook for teaching and learning. Cambridge: Cambridge University Press.

Newman, D. R., Webb, B., \& Cochrane, C. (1995). A content analysis method to measure critical thinking in face-to-face and computer supported group learning. Interpersonal Computing and Technology, 3(2), 56-77.

Nickerson, R. S. (1987). Why teach thinking? In J. B. Baron, \& R. J. Stenberg (Eds.), Teaching Thinking Skills: Theory and Practice (pp. 27-37). New York: W. H. Freeman \& Company.

Norris, S. P., \& Ennis, R. (1989). Evaluating critical thinking. In R. J. Swartz, \& D. N. Perkins (Eds.), The practitioner's guide to teaching thinking series (p. 1). Pacific Grove, CA: Midwest Publication.

Paul, R. W. (1990). Critical thinking. Rohnert Park, CA: Center for Critical Thinking and Moral Critique, Sonoma State University.

Paul, R. W. (1992). Critical thinking: What, why, and how? New Directions for Community Colleges, 77, 3-24.

Paul, R. W. (1993). Critical thinking: What every person needs to survive in a rapidly changing world. Santa Rosa, CA: Foundation for Critical Thinking.

Perkins, D. N. (1987). Thinking frames: An integrative perspective teaching cognitive skills. In J. B. Baron, \& R. J. Stenberg (Eds.), Teaching Thinking Skills: Theory and Practice (pp. 41-61). New York: W. H. Freeman \& Company.

Perkins, D. N., \& Salomon, G. (1989). Are cognitive skills context bound? Educational Researcher, 19(1), 16-25.

Pikkert, J. J., \& Foster, L. (1996). Critical thinking skills among third year Indonesian English Students. RELC Journal, 27, 56-64.

Rasool, J., Banks, C., \& McCarthy, M. J. (2002). Critical Thinking: Reading and writing in a diverse world (2nd ed.). Boston: Thomson Wadsworth.

Royalty, J. (1995). The generalizability of critical thinking: Paranormal beliefs versus statistical reasoning. The Journal of Genetic Psychology, 156(4), 477-487.

Presseisen, B. (1988). Avoiding battle at curriculum gulch: Teaching thinking and content. Educational Leadership, 45, 7-8. Retrieved from http://www.ascd.org/ASCD/pdf/journals/ed_lead/el_198804_ presseisen.pdf

Schneider, V. (2002). Critical thinking in elementary classroom: Problems and solutions. Educators Publishing Service, 1-3. Retrieved from http://eps.schoolspecialty.com/downloads/articles/Critical_ThinkingSchneider.pdf

Behdani, R. S. (2009). The relationship between autonomy, critical thinking ability, and reading comprehension of the Iranian EFL learners (Unpublished master's thesis). Islamic Azad University, Science and Research Campus, Tehran, Iran.

Simpson, E., \& Courtney, M. (2002). Critical thinking in nursing education: A literature review. Retrieved from eprints.qut.edu.au/263/1/simpson_critical_thinking.pdf

Sternberg, R. (2001). Teaching problem solving as a way of life. In A. Costa (Ed.), Developing minds: A resource book for teaching thinking. Alexandria, VA: ASCD.

Wallace, C. (2003). Critical Reading in Language Education. New York: Palgrave MACMILLAN.

Wash, D., \& Paul, R. (1988). The goal of critical thinking: From educational ideal to educational reality. Washington D.C.: American Federation of Teachers. Retrieved from http://files.eric.ed.gov/fulltext/ED295916.pdf

Willingham, D. T. (2007). Critical thinking: Why is it so hard to teach? American Educator, 27, 8-19.

Wood, R. (2002). Critical thinking. Retrieved from http://www.robinwood.com/Democracy/GeneralEssays/ CriticalThinking.pdf 


\section{Copyrights}

Copyright for this article is retained by the author(s), with first publication rights granted to the journal.

This is an open-access article distributed under the terms and conditions of the Creative Commons Attribution license (http://creativecommons.org/licenses/by/3.0/). 